\title{
Path Selection of Multimodal Transport Based on Multi-Objective Mixed Integer Programming
}

\author{
Zhongxin Luo \\ Department of Transportation Planning and Management, College of Transport \& Communications, Shanghai Maritime \\ University, Shanghai, China \\ Email: luozhongxin0517@163.com
}

How to cite this paper: Luo, Z.X. (2019) Path Selection of Multimodal Transport Based on Multi-Objective Mixed Integer Programming. Journal of Transportation Technologies, 9, 462-473. https://doi.org/10.4236/jtts.2019.94029

Received: September 9, 2019

Accepted: September 27, 2019

Published: September 30, 2019

Copyright () 2019 by author(s) and Scientific Research Publishing Inc. This work is licensed under the Creative Commons Attribution International License (CC BY 4.0).

http://creativecommons.org/licenses/by/4.0/

\section{(c) (i) Open Access}

\begin{abstract}
Based on "One Belt and One Road", this paper studies the path selection of multimodal transport by using the method of multi-objective mixed integer programming. Therefore, this paper studies the factors of transportation time, transportation cost and transportation safety performance, and establishes a mathematical model. In addition, the method of multi-objective mixed integer programming is used to comprehensively consider the different emphasis and differences of customers on cargo transportation. Then we use planning tools of Microsoft Excel to solve path selection and to determine whether the chosen path is economical and reliable. Finally, a relatively complex road network is built as an example to verify the accuracy of this planning method.
\end{abstract}

\section{Keywords}

One Belt and One Road, Multi-Objective, Multimodal Transport,

Mixed Integer Programming, Path Selection

\section{Introduction}

Even since the initiative of "One Belt and One Road" was put forward in 2013, the international trade between China and other countries in the world has been increasing day by day. Because One Belt and One Road involves economic exchanges between 65 countries and regions along the route, it is particularly significant for goods trading between countries. A single traditional mode of transport cannot achieve its goals and requirements, so multimodal transport in the field of transport plays an extremely important role.

Since multimodal transport involves multiple modes of transport and multiple routes, it has become a trend to transport goods to their destinations quickly, ef- 
ficiently and safely, thus the selection of multimodal transport routes has become the focus and difficulty in this field. Hence the route selection of multi-objective multi-modal transport becomes the core problem of transportation research.

\section{Literature Review}

With the rapid development of economy, many scholars at home and abroad have studied the optimization of multi-objective multimodal transport path.

Based on some domestic and overseas research results, Seo J and Chen F [1] chose a feasible route from Chongqing to Rotterdam, Netherlands to transport laptop computers by studying the transport cost, transport time and credit index of multi-objective multimodal transport. By studying the transportation cost, transportation time and carbon tax emission, Wanjie, Wei Shuang [2] studied the route selection of multi-objective China-Europe railway containers. Li Yumin, Xiao-yan Guo, Yang [3] studied the central trains of container path selection by analyzing the transport costs, transport time and carbon emissions. Fu Xinping, He Yusha, Zou Min et al. [4] studied the route selection of containers from wuhan to Europe through transport time and cost. Taking Turkey as the research object, Hamdi g. Resat, MetinTurkay [5] solved the network design problem of multimodal transport, established the optimization model and obtained the optimization result by using the transportation time and cost as the target. In the process of transportation, transportation security has always been the first consideration. Wang Yan, et al. [6] established a safety evaluation model by using fuzzy theory according to the problem of road traffic safety at home and abroad. In this model, road safety was taking as the starting point, making it is more conducive to choose the correct route in the transportation process.

Through the above literature analysis, it is found that most studies on multimodal transport route selection aimed at transportation time and cost to establish a model and obtain the optimal solution. Few literatures considered the safety performance of route selection during transportation. Hence this paper aims to build a mathematical model based on the three factors of transportation time, transportation cost and transportation safety, and uses the method of mixed integer programming to choose the optimal path.

\section{Multi-Objective Mixed Integer Programming Model}

\subsection{Multiple Objective Factor Analysis}

The multi-objective factors selected in this paper include: transportation time, transportation cost, and transportation safety, among which:

1) Transport time includes:

From city node $I$ to $j$, the time of transportation mode $k$,

In city node $I$, the time of converting transportation mode $k$ to $h$;

Cargo stay time at city node $I$.

2) Transportation cost includes: 
From city node $I$ to $j$, the cost of using $k$ transportation mode;

In city node $I$, the cost of changing the mode of transportation $k$ to $h$ (if there is a change of loading, that is, multiplying by coefficient 1; otherwise, it is 0 );

The actual arrival time exceeds the expected time of arrival cost.

3) The safety of transportation includes:

There are many safety coefficients affecting the transport of goods, including goods themselves, people, transport mode, road conditions, environment and management factors [7], etc. Therefore, there will be many fuzzy logic variables and fuzzy functions when quantifying the transport safety. In addition, this paper mainly focuses on route selection, and international transportation of goods is mainly based on containers. Through fuzzy logic algorithm theory, we combined factors such as the type of goods, drivers and transportation environment; using the hierarchical analysis of traffic safety, the safety coefficient of transportation was determined mainly by selecting a certain mode of transportation, so as to determine which mode of transportation should be selected to meet the safety requirements of customers when transporting goods between urban nodes.

Among them, the theory of fuzzy logic algorithm uses fuzzy logic variables and fuzzy logic functions to solve the problem of fuzziness, and points out the direction for the research target from the logic idea.

In this paper, we intend to regard container transport as the research object, among which the modes of multimodal transport of container include highway, railway and waterway transport. Based on the comparison of the technical and economic characteristics of various transportation modes studied by Zhao wenjuan [8] of Chang'an university, it can be known that the safety of the three transportation modes is from high to low as: railway $>$ waterway $>$ highway. Due to more human factors influence to the road and long-distance goods transport dominant position, the safety coefficient of highway is low. Chen Yang et al. [9] used fuzzy algorithm to analyze the selection of transportation modes with characteristics of transportation demand, analyzed the weight of each transportation mode, and took transportation safety into account in the literature through fuzzy algorithm, and finally obtained the safety coefficient of various transportation modes (Table 1).

\subsection{Construction of Mixed Integer Programming Model}

According to the city node on the transportation network, we choose the route of goods from the starting point to the destination, and select the corresponding city node, so as to minimize the time and cost of goods transportation, which constitutes the transportation path of goods. Suppose a batch of goods is transported from the starting point $\mathrm{A}$ to the destination $\mathrm{C}$, along the way, it can pass through $\mathrm{N}$ urban nodes called $\mathrm{B}$, each node has $\mathrm{M}$ city route selection mode of transportation. Furthermore, the goods can only transfer and transform the mode of transportation in the urban nodes, then the transport path of goods is 
Table 1. Safety coefficients of various transportation modes.

\begin{tabular}{cc}
\hline The mode of transportation & Safety coefficient \\
\hline railway & 0.4 \\
waterway & 0.39 \\
highway & 0.21 \\
\hline
\end{tabular}

Note: the size of safety performance shows that the safety performance of the goods is greater when the transport transit is the smallest.

constructed in this way. Among them, there are four modes of transportation between urban nodes, namely highway, railway, airway and waterway. And there is an expected value for the time that takes to transport the goods. When the expected value is exceeded, a certain cost (called time loss cost) is charged. Therefore, this paper takes the time, cost and safety of transportation as the main factors to select the optimal city node in the combined transport network to form an optimal path. This is shown in Figure 1.

1) Fixed rules

a) In the process of transportation, goods can only choose one mode of transportation between two adjacent nodes.

b) In the process of transportation, if the goods need to be transferred, this process can only happen at the city node, and only once.

c) Considering the transportation of containers, any node city can only provide three modes of transportation, namely, railway, highway and waterway.

d) In transportation, the object is a whole and cannot be divided into multiple parts.

2) Establish mathematical model

Select the corresponding city node as the decision variable $x_{i, j}^{k}$ (The transport mode between nodes is 1 at the same time; otherwise, it is 0 ); Variable $y_{i}^{k, h}$ is 1 if the means of transport changes at the node, otherwise 0 .

a) Transit time

i) The goods are transported from $i$ to $j$, and the time of using means of transportation $k$ is $T_{1}$ :

$$
T_{1}=\sum_{i, j \in N} \sum_{k \in Y} t_{i, j}^{k} x_{i, j}^{k}
$$

ii) When the goods are at city node $i$, the time of switching means from transport $k$ to transport $h$ is $T_{2}$ :

$$
T_{2}=\sum_{i \in N} \sum_{k, h \in Y} Q t_{i}^{k, h} y_{i}^{k, h}
$$

iii) The residence time of a single cargo at city node is $T_{3}$ :

$$
T_{3}=t_{i}^{p}
$$

Therefore, the total time in the transportation process should be the minimum, that is:

$$
\begin{aligned}
T_{\text {total }} & =\min \left(T_{1}+T_{2}+T_{3}\right) \\
& =\min \left\{\sum_{i, j \in N} \sum_{k \in Y} t_{i, j}^{k} x_{i, j}^{k}+\sum_{i \in N} \sum_{k, h \in Y} Q t_{i}^{k, h} y_{i}^{k, h}+t_{i}^{p}\right\}
\end{aligned}
$$




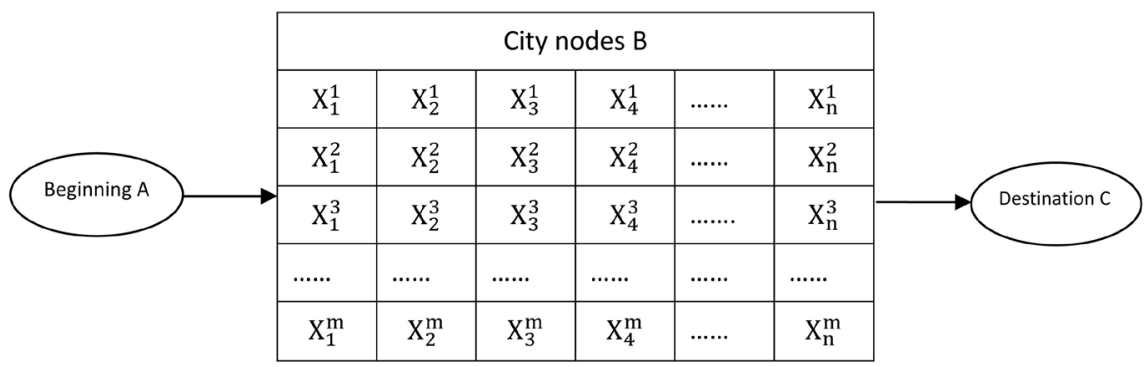

Figure 1. Basic line network.

where:

$i, j$-represents the urban node set $N=\{1,2,3, \cdots\}$;

$k, h$-represents a collection of different modes of transport $Y=\{1,2,3, \cdots\}$;

$t_{i, j}^{k}$-represents the transportation time from the city node $i$ to the city node $j$ using the transportation mode $k$,

$Q$-represents the quantity of goods;

$t_{i}^{k, h}$-represents the time taken to convert transportation mode $k$ to $h$ at city node $i$

$t_{i}^{p}$-duration of cargo stay at city node $i$.

b) Cost of transportation

i) The cost of transporting single goods from city node $i$ to city $j$ using $k$ mode is $C_{1}$ :

$$
C_{1}=\sum_{i, j \in N} \sum_{k \in Y} Q c_{i, j}^{k} l_{i, j}^{k} x_{i, j}^{k}
$$

ii) The cost of changing the mode of transportation $k$ to $h$ is $C_{2}$ :

$$
C_{2}=\sum_{i \in N} \sum_{k, h \in Y} Q c_{i}^{k, h} y_{i}^{k, h}
$$

iii) The expected time of arrival and the cost of actual time of arrival are $C_{3}$ : Suppose the expected arrival time interval is $[u, v]$, actual arrival time is $T$.

$$
C_{3}= \begin{cases}\alpha(u-T) Q & T<u \\ 0 & T \in[u, v] \\ \beta(T-v) Q & T>v\end{cases}
$$

Therefore, the total cost of completing a transport should be the minimum:

$$
\begin{aligned}
C_{\text {total }} & =\min \left(C_{1}+C_{2}+C_{3}\right) \\
& =\min \left(\sum_{i, j \in N} \sum_{k \in Y} Q c_{i, j}^{k} l_{i, j}^{k} x_{i, j}^{k}+\sum_{i \in N} \sum_{k, h \in Y} Q c_{i}^{k, h} y_{i}^{k, h}+C_{3}\right)
\end{aligned}
$$

where:

$c_{i, j}^{k}$-represents the cost of transportation mode $k$ for single goods from city node $i$ to city node $j$

$l_{i, j}^{k}$-represents the transportation distance from city node $i$ to city node $j ;$

$c_{i}^{k, h}$-represents the cost of switching from transportation mode $k$ to transportation mode $h$ at city node $i$;

$\alpha$-represents the cost per unit of wait;

$\beta$-represents the cost of punishment over expected time.

c) Safety of transportation 


$$
S=\max \left\{\sum_{i, j \in N} \delta_{i, j}^{k} x_{i, j}^{k}-\partial_{i}^{k, h} y_{i}^{k, h}\right\}
$$

where:

$\delta_{i, j}^{k}$-represents the safety coefficient of traffic mode $k$ from city node $i$ to city node $j$.

$\partial_{i}^{k, h}$-represents the reduction coefficient of turning traffic mode $k$ into $h$ at city node $i$, which is usually 0.50 .

In conclusion, the constraint conditions of this problem are:

$$
\begin{gathered}
\sum_{k \in Y} x_{i, j}^{k}=1, \quad \forall i, j \in N \\
\sum_{k, h \in Y} y_{i}^{k, h}=1, \quad \forall i \in N \\
x_{i, j}^{k}, y_{i}^{k, h} \in\{0,1\}
\end{gathered}
$$

\section{Model Solution Steps}

A relatively simple method can be used to solve multi-objective programming, namely Excel, which evolved through linear programming. The programming and solving tool of Mircrosoft Excel came from the nonlinear optimization code jointly developed by Leon and Allan from the university of Texas and Cleveland state university. By loading the program solver, the optimal solution can be achieved.

Because the multi-objective problem needs to be solved in this paper, the multi-objective model can be expressed in the form of matrix through the knowledge of operations research. The multi-objective model is described below:

$$
\begin{array}{ll}
\min & Z=P\left(d_{i}^{+}, d_{i}^{-}\right) \\
\text {s.t. } & A x-d_{i}^{+}+d_{i}^{-}=b \\
& x \geq 0, d_{i}^{+} \geq 0, d_{i}^{-} \geq 0
\end{array}
$$

where, $d_{i}^{+}, d_{i}^{-}$represent the positive and negative deviation values respectively, and $P$ represents the priority of targets at all levels.

Using excel to solve multi-objective integer programming, the weight of each target should be determined first, and then the optimal solution of each target can be obtained according to the weight. The specific steps are shown in Figure 2 frame diagram.

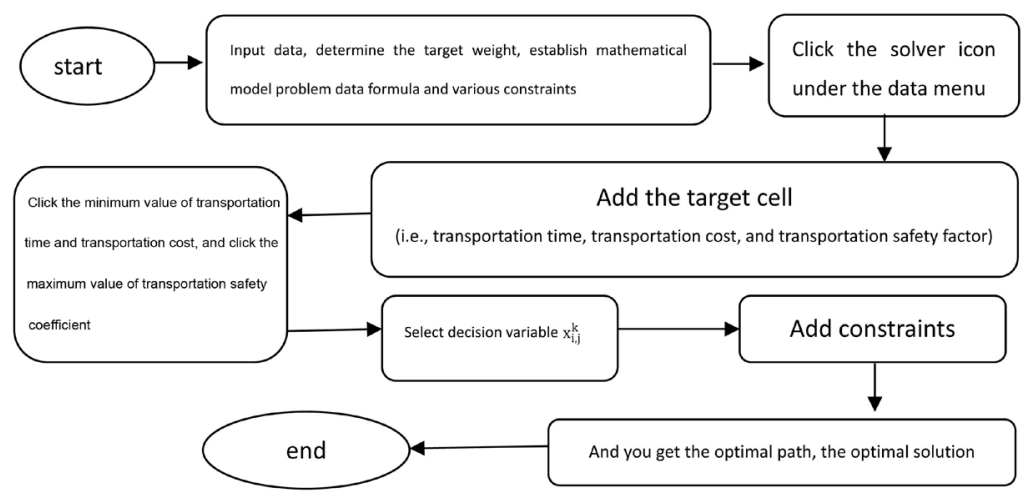

Figure 2. Step framework. 


\section{The Example Analysis}

Since transportation time, transportation cost and transportation safety are mutually exclusive, in order to verify the reliability of the model and get closer to the authenticity, it is assumed that the following figure shows the virtual complex road network of transportation. Then choose the route based on the different requirements of different users. The data of unit cost, transportation speed, transfer fee and time of the following transportation modes are obtained through the railway transportation website of ministry of railways, China highway network and shipping website.

Combined with different transportation objectives of different goods, there are seven forms as follows:

1) Minimum transport time;

2) Minimum transportation cost;

3) High safety coefficient;

4) Minimum transportation time and cost;

5) Minimum transportation cost and high safety coefficient;

6) Shortest transportation time and high safety coefficient;

7) Low transportation cost, short transportation time and high safety coefficient.

Solution steps:

1) Set the parameters:

Suppose the transportation quantity $Q=6 \mathrm{Teu}$, where the weight of the container is $20 \mathrm{t} / \mathrm{Teu}$. The corresponding penalty coefficient is: $\alpha=60, \beta=90$; (Among them, Numbers 1 - 11 are domestic city nodes and Numbers $11-15$ are foreign city nodes). Due to different transportation modes of each node, the distance is also different. In order to simplify operation, the transportation distance of each transportation mode between nodes is generated by random Numbers (Figure 3).

The mode of transportation between cities is shown in Table 2.

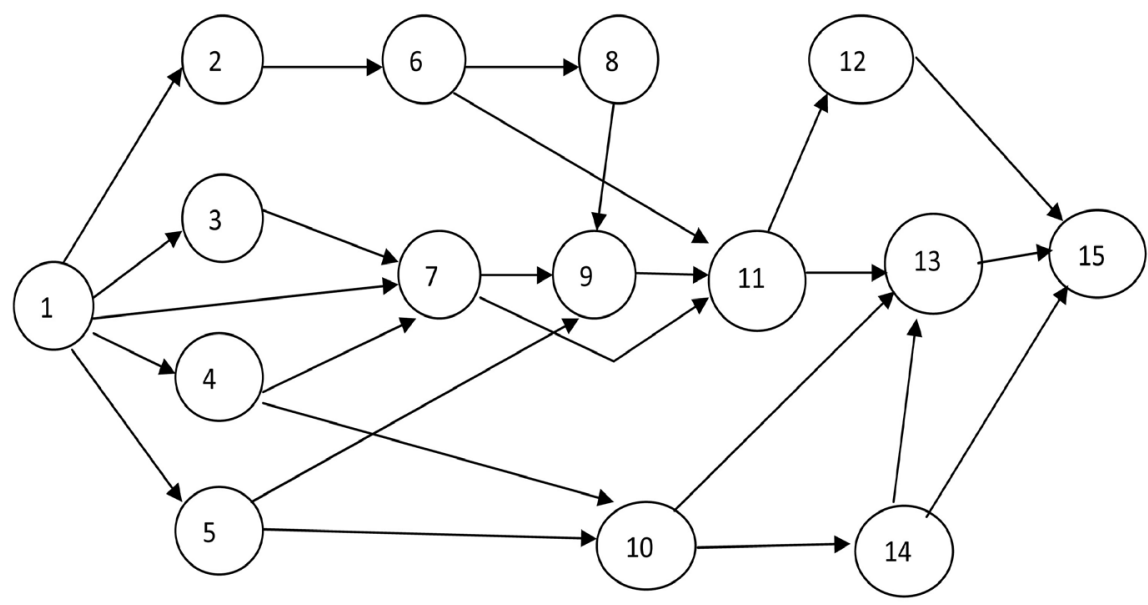

Figure 3. Virtual road network diagram. 
Table 2. Transportation modes between nodes.

\begin{tabular}{cccccc}
\hline Lines & $\begin{array}{c}\text { The mode of } \\
\text { transportation }\end{array}$ & Lines & $\begin{array}{c}\text { The mode of } \\
\text { transportation }\end{array}$ & Lines & $\begin{array}{c}\text { The mode of } \\
\text { transportation }\end{array}$ \\
\hline $1-2$ & H/R/W & $5-9$ & $\mathrm{R}$ & $10-14$ & $\mathrm{~W}$ \\
$1-3$ & $\mathrm{H} / \mathrm{R}$ & $5-10$ & $\mathrm{H} / \mathrm{R} / \mathrm{W}$ & $11-12$ & $\mathrm{R}$ \\
$1-4$ & $\mathrm{H} / \mathrm{R}$ & $6-8$ & $\mathrm{H} / \mathrm{R} / \mathrm{W}$ & $11-13$ & $\mathrm{R}$ \\
$1-5$ & $\mathrm{H} / \mathrm{R} / \mathrm{W}$ & $6-11$ & $\mathrm{H} / \mathrm{R}$ & $12-15$ & $\mathrm{H} / \mathrm{R}$ \\
$1-7$ & $\mathrm{H} / \mathrm{R}$ & $7-9$ & $\mathrm{H} / \mathrm{R}$ & $13-15$ & $\mathrm{H} / \mathrm{R}$ \\
$2-6$ & $\mathrm{H} / \mathrm{R} / \mathrm{W}$ & $7-11$ & $\mathrm{H} / \mathrm{R}$ & $14-13$ & $\mathrm{~W}$ \\
$3-7$ & $\mathrm{H} / \mathrm{R}$ & $8-9$ & $\mathrm{H} / \mathrm{R}$ & $14-15$ & $\mathrm{H} / \mathrm{R}$ \\
$4-7$ & $\mathrm{R}$ & $9-11$ & $\mathrm{H} / \mathrm{R}$ & & \\
$4-10$ & $\mathrm{~W}$ & $10-13$ & $\mathrm{~W}$ & & \\
\hline
\end{tabular}

Note: $\mathrm{H}$ stands for road transport; $\mathrm{R}$ for rail transport; $\mathrm{W}$ for water transport.

2) Input data:

(data source: railway transport website, China highway network, shipping website, international container transport charging rules)

a) The cost of transportation: (Table 3);

b) Transportation speed: (Table 4);

c) Transfer charge: (Table 5);

d) Transit time: (Table 6);

e) Safety factor: (Table 7).

3) Get the result:

According to the model algorithm, the route where the user's requirements for cargo transportation are obtained is:

a) minimum transportation time;

b) Optimal path: $1 \rightarrow 7 \rightarrow 11 \rightarrow 13 \rightarrow 15$ (Table 8);

c) minimum transportation cost;

d) Optimal path: $1 \rightarrow 5 \rightarrow 10 \rightarrow 13 \rightarrow 15$ (Table 9);

4) Good safety coefficient:

Optimal path: $1 \rightarrow 7 \rightarrow 11 \rightarrow 13 \rightarrow 15$ (Table 10);

5) minimum transportation time and cost (Table 11):

Optimal path: $1 \rightarrow 2 \rightarrow 6 \rightarrow 11 \rightarrow 12 \rightarrow 15$;

6) minimum transportation cost and high safety coefficient (Table 12):

Optimal path: $1 \rightarrow 2 \rightarrow 6 \rightarrow 11 \rightarrow 12 \rightarrow 15$;

7) The shortest transportation time and high safety coefficient (Table 13):

Optimal path: $1 \rightarrow 7 \rightarrow 11 \rightarrow 13 \rightarrow 15$;

8) low transportation cost, short transportation time and high safety coefficient (Table 14):

Optimal path: $1 \rightarrow 2 \rightarrow 6 \rightarrow 11 \rightarrow 12 \rightarrow 15$. 
Table 3. Domestic and foreign transportation costs of different transportation modes.

\begin{tabular}{ccc}
\hline The mode of transportation & $\begin{array}{c}\text { Domestic-Domestic } \\
(\$ /(\mathrm{t} \cdot \mathrm{km}))\end{array}$ & $\begin{array}{c}\text { Domestic-Foreign } \\
(\$ /(\mathrm{t} \cdot \mathrm{km}))\end{array}$ \\
\hline Highway & 0.05 & 0.05 \\
Railway & 0.04 & 0.04 \\
Waterway & 0.045 & 0.022 \\
\hline
\end{tabular}

Table 4. Domestic and foreign transportation speeds of different transportation modes.

\begin{tabular}{cc}
\hline The mode of transportation & Average transport speed $(\mathrm{km} / \mathrm{h})$ \\
\hline Railway & 35 \\
Waterway & 12.5 (Domestic-Domestic) $/ 27.5$ (Domestic-Foreign) \\
Highway & 47.5 \\
\hline
\end{tabular}

Table 5. Transit costs of each mode of transport (Unit: yuan/t).

\begin{tabular}{cccc}
\hline The mode of transportation & Highway & Railway & Waterway \\
\hline Highway & 0 & 2.5 & 2.6 \\
Railway & 2.5 & 0 & 3.5 \\
Waterway & 2.6 & 3.5 & 0 \\
\hline
\end{tabular}

Table 6. Each mode of transportation transit time (Unit: hour/Teu).

\begin{tabular}{cccc}
\hline The mode of transportation & Highway & Railway & Waterway \\
\hline Highway & 0 & 0.2 & 0.34 \\
Railway & 0.2 & 0 & 0.45 \\
Waterway & 0.34 & 0.45 & 0 \\
\hline
\end{tabular}

Table 7. Safety factors of the mode of transportation.

\begin{tabular}{cc}
\hline The mode of transportation & Safety coefficient \\
Railway & 0.40 \\
Waterway & 0.39 \\
Highway & 0.21 \\
\hline
\end{tabular}

Table 8. Focuses on the transport schemes with the least transport time.

\begin{tabular}{cc}
\hline The mode of transportation & $1-7$ (Highway), $7-11$ (Railway), \\
$11-13$ (Railway) $13-15$ (Highway)
\end{tabular}


Table 9. Focuses on the least expensive transport options.

\begin{tabular}{cc}
\hline The mode of transportation & $1-5$ (Waterway), $5-10$ (Waterway), \\
& $10-13$ (Waterway), $13-15$ (Railway) \\
\hline Transportation costs (\$) & 22735.725 \\
Transportation time (h) & 1232.985 \\
Safety performance & 1.07 \\
\hline
\end{tabular}

Table 10. Focuses on the best safety coefficient transport scheme.

\begin{tabular}{cc}
\hline The mode of transportation & $1-7$ (Railway), $7-11$ (Railway), \\
& $11-13$ (Railway) $13-15$ (Railway) \\
\hline Transportation costs (\$) & 39254.4 \\
Transportation time (h) & 599.31 \\
Safety performance & 1.6 \\
\hline
\end{tabular}

Table 11. Focuses on the transport schemes with the lowest transport time and transport cost.

\begin{tabular}{cc}
\hline The mode of transportation & $1-2$ (Railway) $2-6$ (Railway) 6 - 11 (Railway) 11 \\
\hline Transportation costs (\$) & 36204.795 \\
Transportation time (h) & 688.905 \\
Safety performance & 1.31 \\
\hline
\end{tabular}

Table 12. Focuses on transportation schemes with the least transportation cost and high safety coefficient.

\begin{tabular}{cc}
\hline The mode of transportation & $1-2$ (Waterway) $2-6$ (Waterway) $6-11$ \\
& (Railway) $11-12$ (Railway) $12-15$ (Railway) \\
\hline Transportation costs (\$) & 34796.265 \\
Transportation time (h) & 815.52 \\
Safety performance & 1.48 \\
\hline
\end{tabular}

Table 13. Focuses on transportation schemes with the shortest transportation time and high safety coefficient.

\begin{tabular}{cc}
\hline The mode of transportation & $\begin{array}{c}1-7 \text { (Railway) }, 7-11 \text { (Railway), } 11-13 \\
\text { (Railway) } 13-15 \text { (Railway) }\end{array}$ \\
\hline Transportation costs (\$) & 39254.4 \\
Transportation time (h) & 599.31 \\
Safety performance & 1.6 \\
\hline
\end{tabular}

Table 14. Focuses on transportation schemes with low transportation cost, short transportation time and high safety coefficient.

\begin{tabular}{cc}
\hline The mode of transportation & $\begin{array}{c}1-2 \text { (Waterway) } 2-6 \text { (Waterway ) } 6-11 \\
\text { (Railway) } 11-12 \text { (Railway) } 12-15 \text { (Railway) }\end{array}$ \\
\hline Transportation costs (\$) & 34796.265 \\
Transportation time (h) & 815.52 \\
Safety performance & 1.48 \\
\hline
\end{tabular}




\section{Conclusions}

This paper comprehensively considers the three aspects of transport time, cost and safety performance of multimodal transport to select the optimal route for cargo transport. Using the programming and solving tool of Microsoft Excel, the priority of all levels of targets was determined. Through the method of multi-objective mixed integer programming, we finally get the best route of each target priority. Include:

1) When the transportation time is the least, the route and mode of transportation are 1 - 7 (highway) 7 - 11 (railway) 11 - 13 (railway) $13-15$ (highway). The transportation cost is $\$ 42782.415$, the transportation time is 357.71 hours, and the safety is 0.54 .

2) When the transportation cost is the lowest, the route and mode of transportation are 1 - 5 (waterway) 5 - 10 (waterway) $10-13$ (waterway) 13 - 15 (railway). The transportation cost is $\$ 22735.725$, the transportation time is 1232.985 hours, and the safety is 1.07 .

3) When the safety factor is high, the route and mode of transportation are 1 7 (railway) 7 - 11 (railway) 11 - 13 (railway) 13 - 15 (railway). The transportation cost is $\$ 39254.4$, the transportation time is 599.31 hours, and the safety is 1.6.

4) When the transportation time and cost are the least, the route and mode of transportation are 1 - 2 (railway) 2 - 6 (railway) 6 - 11 (railway) 11 - 12 (railway) 12 - 15 (highway). The transportation cost is $\$ 36204.975$, the transportation time is 688.905 hours, and the safety is 1.31 .

5) When the transportation cost is the lowest and the safety factor is high, the route and mode of transportation are $1-2$ (waterway) $2-6$ (waterway) $6-11$ (railway) 11 - 12 (railway) 12 - 15 (railway). The transportation cost is $\$ 3476.265$, the transportation time is 815.52 hours, and the safety is 1.48 .

6) When the transportation time is the shortest and the safety factor is high, the route and mode of transportation are: $1-7$ (railway) 7 - 11 (railway) $11-13$ (railway) 13 - 15 (railway). The transportation cost is $\$ 39254.4$, the transportation time is 599.31 hours, and the safety is 1.6.

7) When the transportation cost is low, the transportation time is short and the safety factor is high, the route and mode of transportation are 1 - 2 (railway) 2 - 6 (railway) 6 - 11 (railway) $11-12$ (railway) $12-15$ (highway). The transportation cost is $\$ 3476.265$, the transportation time is 815.52 hours, and the safety is 1.48 .

The method discussed in this paper scientifically and accurately solves the demand of path selection of goods transportation by users.

Since there are many factors affecting the safety of cargo transportation described in this paper, it is difficult to comprehensively consider the overall situation. Therefore, for future studies, some safety coefficients can be further subdivided, the algorithm model for safety description can be optimized and improved, and a better selection scheme can be proposed based on the types of cargo. 


\section{Conflicts of Interest}

The author declares no conflicts of interest regarding the publication of this paper.

\section{References}

[1] Seo, Y.J., Chen, F. and Roh, S.Y. (2017) Multimodal Transportation: The Case of Laptop from Chongqing in China to Rotterdam in Europe. Asian Journal of Shipping \&Logistics, 33, 155-165. https://doi.org/10.1016/j.ajsl.2017.09.005

[2] Wan, J. and Wei, S. (2019) Research on Route Selection of Multiobjective Multimodal Transport Based on Hybrid Algorithm. Journal of Tianjin University (Natural Science and Engineering Technology Edition), 52, 285-292.

[3] Li, Y.M., Guo, X.Y. and Yang, L. (2017) Selection of Multi-Objective Multimodal Transport Route for China Europe Containers. Journal of Railway Science and Engineering, 14, 2239-2248.

[4] Fu, X.-P., He, Y.-S., Zou, M., et al. (2017) Research on Selection of International Container Multimodal Transport Lines. Railway Transport and Economy, 39, 12-17.

[5] Resat, H.G. and Turkay, M. (2015) Design and Operation of Intermodal Transportation Network in the Marmara Region of Turkey. Transportation Research Part E: Logistics and Transportation Review, 83, 16-33. https://doi.org/10.1016/j.tre.2015.08.006

[6] Wang, Y. and Guo, Z.Y. (2008) Road Traffic Safety Evaluation Method Based on Fuzzy Logic Theory. Journal of Tongji University (Natural Science Edition), 36, 47-51.

[7] Song, X.Y. (2017) Definition and Analysis of Road Traffic Safety Research Content. Practical Automobile Technology, 11, 87-89.

[8] Zhao, W.J. (2017) Comparison of Technical and Economic Characteristics of Various Transportation Modes. Cooperative Economy and Technology, 3, 38-39.

[9] Chen, Y., Zhou, X.H. and Ye, H.Z. (2010) Research on Transportation Mode Selection Based on Transport Demand Characteristics. Railway Freight, 3, 14-17. 